\title{
Phospholipid Liposomes Acquire Apolipoprotein E in Atherogenic Plasma and Block Cholesterol Loading of Cultured Macrophages
}

\author{
Kevin Jon Williams, Alan R. Tall, Charles Bisgaier, and Robert Brocia \\ Department of Medicine, Columbia University, College of Physicians \& Surgeons, New York 10032
}

\begin{abstract}
A single infusion of phospholipid liposomes promptly and persistently abolished the ability of hypercholesterolemic rabbit plasma to cause cholesteryl ester loading in cultured macrophages. This phospholipid enrichment of plasma caused moderate stimulation of cellular cholesterol efflux and, unexpectedly, almost complete inhibition of cellular uptake of $\beta$-very low density lipoprotein ( $\beta$-VLDL), the major cholesteryl ester-rich particle in hypercholesterolemic rabbit plasma. Cell viability and LDL receptor activity were unaffected. Incubation of liposomes with $\beta$-VLDL resulted in transfer of apolipoprotein-E (apoE) to the liposomes; reisolated apoE-phospholipid liposomes then competed efficiently for cellular apoprotein receptors. Thus, a major mechanism by which phospholipid infusions result in diminished accumulation of cholesteryl ester in cultured macrophages is by blocking cellular uptake of $\beta$-VLDL. The liposomes deplete $\beta$-VLDL of apoE, then compete for receptor-mediated uptake. These results suggest a novel mechanism contributing to the known antiatherogenic effect of phospholipid infusions: infused liposomes acquire apoE, then block uptake of atherogenic lipoproteins by arterial wall macrophages.
\end{abstract}

\section{Introduction}

Cholesterol-fed rabbits develop deposits of cholesterol in their arterial walls and have been used extensively as an experimental model of atherosclerosis. The deposits of cholesterol result from uptake by vessel wall macrophages of $\beta$-very low density lipoprotein $(\beta$-VLDL), the major cholesteryl ester-rich lipoprotein in the plasma of cholesterol-fed rabbits (1). Macrophage uptake of $\beta$-VLDL is mediated by a cell surface receptor that is immunologically identical to the $\mathrm{LDL}$ receptor but displays different functional properties (2).

Three decades ago, repeated intravenous administration of dispersed phospholipid was shown to produce rapid, substantial shrinkage of atherosclerotic deposits in cholesterol-fed rabbits (3). This result has been confirmed by several laboratories using a variety of animal models (4-11). Phospholipid infusions have recently been shown to result in the appearance of vesicular lipoproteins in plasma (12). The vesicular lipoproteins remove cholesterol from other lipoproteins and from tissues (12) and they acquire apolipoprotein (apo) $E^{1}$ and bind to $L D L$ receptors

Address reprint requests to Dr. Williams.

Received for publication 28 October 1986.

1. Abbreviations used in this paper: apo, apolipoprotein; DMEM, Dulbecco's modified Eagle's medium; fBSA, fatty acid free bovine serum albumin.

J. Clin. Invest.

(c) The American Society for Clinical Investigation, Inc.

$0021-9738 / 87 / 05 / 1466 / 07 \quad \$ 1.00$

Volume 79, May 1987, 1466-1472
(13). These observations support the hypothesis that the antiatherogenic effect of phospholipid infusions results in part from uptake of tissue cholesterol by vesicular lipoproteins, with reverse cholesterol transport to the liver mediated perhaps by hepatic apolipoprotein receptors (11).

The most striking examples of phospholipid-induced regression of experimental atherosclerosis were those in which regression was shown to occur even while the animals were maintained on the high cholesterol diets $(9,10)$. Thus, the phospholipid infusions converted highly atherogenic plasma into antiatherogenic plasma. Using cultured macrophages as a model of the macrophages in the arterial wall, we investigated the effect of phospholipid infusions on the ability of hypercholesterolemic rabbit plasma to cause cellular cholesterol loading and efflux. We found that phospholipid enrichment of plasma produced a moderate enhancement of cellular cholesterol efflux in vitro. However, added phospholipid liposomes unexpectedly produced a dramatic inhibition in cellular uptake of the atherogenic $\beta$ VLDL particles.

A preliminary report of this work was presented at the 59th Scientific Sessions of the American Heart Association (14).

\section{Methods}

Lipoproteins and liposomes. Rabbit $\beta$-VLDL $(d<1.006 \mathrm{~g} / \mathrm{ml})$ was prepared by ultracentrifugation of hypercholesterolemic rabbit plasma. Human LDL $(d=1.019-1.063 \mathrm{~g} / \mathrm{ml})$ was prepared by ultracentrifugation of fresh human plasma (15). Acetyl-LDL was prepared by reaction with acetic anhydride (16).

Radioiodinated $\beta$-VLDL and LDL were prepared by a modification of the iodine monochloride method (17). By dodecyl sulfate-polyacrylamide gel electrophoresis (18) of the ${ }^{125} \mathrm{I}-\beta$-VLDL, $71.0 \%$ of recovered radioactivity was in apoB, $6.6 \%$ was in apoE, $4.5 \%$ in apoA-I, and $6.0 \%$ in C-apoproteins. $\left[7-{ }^{3} \mathrm{H}\right]$ Cholesteryl ester-labeled $\beta$-VLDL, LDL, and acetyl-LDL were prepared by incubation with labeled HDL (19) and cholesteryl ester transfer protein, followed by ultracentrifugal reisolation of the less dense lipoproteins. By silica-gel thin-layer chromatography (20), $>98 \%$ of tritium in the labeled $\beta$-VLDL, LDL, and acetyl-LDL was in cholesteryl ester.

$10 \%$ (wt/vol) dispersions of chromatographically pure egg phosphatidylcholine (Sigma Chemical Co., St. Louis, MO, catalogue No. P-2772) in physiologic saline $(0.9 \%)$ were prepared by ultrasonic irradiation at $0^{\circ} \mathrm{C}$ under argon for a total of $40 \mathrm{~min}$, followed by centrifugation to remove fragments of titanium shed by the sonicator probe (21). The sonicated phosphatidylcholine was then sterilized by passage through a $0.45-\mu \mathrm{m}$ filter (Millex-GS, Millipore Corp., Bedford, MA). Sonicated phosphatidylcholine liposomes were always used within $24 \mathrm{~h}$ of preparation.

Rabbits. New Zealand white rabbits were given a cholesterol-enriched diet $(0.5 \%)$ to raise plasma cholesterol concentrations to $7-12 \mathrm{mmol} /$ liter. These cholesterol-fed rabbits were each given a single bolus infusion of $300-400 \mathrm{mg}$ of phosphatidylcholine liposomes per kilogram of body weight. Plasma was always obtained just before $(t=0 \mathrm{~h})$ and $20 \mathrm{~min}$ after each bolus infusion. In a long-term experiment, plasma was also obtained at 1, 2, 4, 8, and $24 \mathrm{~h}$ after the bolus infusion. Plasma cholesterol, 
cholesteryl ester, and lipid phosphorus were measured by standard assays (22-24).

Cultured macrophages. Two types of cultured macrophages were used: the $\mathbf{J 7 7 4}$ macrophage-like tumor line, which accumulates cytoplasmic droplets of cholesteryl ester when incubated with $\beta$-VLDL, acetyl-LDL, or unmodified LDL (25), and the resident mouse peritoneal macrophage, which accumulates cholesteryl ester when incubated with $\beta$-VLDL or acetyl-LDL $(1,26)$. Monolayer cultures of the J774 macrophages were maintained in Dulbecco's modified Eagle's medium (DMEM) supplemented with $10 \%$ (vol/vol) fetal calf serum (FCS). Resident mouse peritoneal macrophages were prepared as needed by cold saline irrigation of the peritoneal cavities of sacrificed mice. Macrophages were separated from other peritoneal cells by their ability to adhere firmly to plastic wells during a 2-h incubation at $37^{\circ} \mathrm{C}(27)$.

$\mathrm{J} 774$ cells were plated into $35-\mathrm{mm}$ dishes, then loaded with $\left[{ }^{3} \mathrm{H}\right]$ cholesterol by either an 18-h incubation in DMEM/FCS with [ 7 $\left.{ }^{3} \mathrm{H}\right)$ cholesteryl ester]-LDL $(0.6 \mathrm{mg}$ protein $/ \mathrm{ml})$ or by a $2-\mathrm{h}$ incubation in DMEM/FCS with $\left[\left(7-{ }^{3} \mathrm{H}\right)\right.$ cholesteryl ester]-acetyl-LDL $(10 \mu \mathrm{g}$ protein/ $\mathrm{ml})$. Radioactive media were then removed from each dish, and the cells were washed three times in phosphate-buffered saline ( $\mathrm{pH}$ 7.4).

To assess the ability of pre- and postinfusion hypercholesterolemic rabbit plasma to cause cellular cholesterol loading and cholesterol efflux, the labeled $\mathbf{J} 774$ cells were incubated for $18 \mathrm{~h}$ in DMEM supplemented with fatty acid-free bovine serum albumin (fBSA) (control medium) or in control medium supplemented with $10 \%(\mathrm{vol} / \mathrm{vol})$ pre- or postinfusion hypercholesterolemic rabbit plasma. Additional wells of labeled cells were incubated in control medium supplemented with preinfusion plasma plus $0.6 \mathrm{mg}$ liposomal phospholipid/ml, or with liposomes without plasma.

Cells were then scraped into the media, and media and cells were separated by low-speed centrifugation. Cells were resuspended in buffe and repelleted three times to remove any residual media. Cells and media were separately counted for ${ }^{3} \mathrm{H}$-radioactivity; the percentage of total radioactivity (i.e., in cells plus media) remaining in the cells was computed for each well. Cells were assayed for protein by the method of Lowry et al. (28) and for total and unesterified cholesterol by gas-liquid chromatography using $\beta$-sitosterol as an internal standard (23). Cholesteryl ester content was calculated as the difference between total and unesterified cholesterol. Cholesterol values were normalized for cellular protein content. Cellular viabilities were determined by trypan blue exclusion (29).

Analogous experiments were performed with mouse peritoneal macrophages. Mouse peritoneal macrophages were loaded with $\left[{ }^{3} \mathrm{H}\right]$ cholesterol by a 2.5 -h incubation in $\left[\left(7-{ }^{3} \mathrm{H}\right)\right.$ cholesteryl ester]-acetyl$\mathrm{LDL}(10 \mu \mathrm{g}$ protein $/ \mathrm{ml})$. These labeled macrophages were then incubated in DMEM/0.1\% fBSA without supplementation (control) or in control medium supplemented with $\beta$-VLDL alone or with $\beta$-VLDL and added liposomes. Cellular cholesterol masses, viabilities, retained ${ }^{3} \mathrm{H}$ radioactivity were measured as described above.

Direct measurement of cellular uptake and degradation of $\beta-V L D L$. ${ }^{125} \mathrm{I}-\beta$-VLDL was incubated with $\mathrm{J} 774$ or mouse peritoneal macrophages in DMEM with or without plasma, and with or without added liposomes. Cell association of ${ }^{125} \mathrm{I}-\beta$-VLDL was determined by measuring cellular ${ }^{125}$ I-radioactivity (30). Degradation of ${ }^{125} \mathrm{I}-\beta$-VLDL was determined by measuring the release of trichloroacetic acid-soluble, chloroform-insoluble

${ }^{125}$ I-radioactivity into the media. Cell-specific degradation was calculated by subtracting spontaneous degradation measured in cell-free wells from the total degradation measured in the presence of cells (30). Spontaneous degradation was at most $3.2 \mathrm{ng}{ }^{125} \mathrm{I}-\beta$-VLDL protein per $35-\mathrm{mm}$ tissue culture well. These cell-association and degradation data reflect primarily the catabolism of apoB, which contained most of the radioactivity in the ${ }^{125} \mathrm{I}-\beta$-VLDL. Cell association was determined for $\left[\left(7-{ }^{3} \mathrm{H}\right)\right.$ cholesteryl ester]- $\beta$-VLDL by measuring cellular ${ }^{3} \mathrm{H}$ radioactivity.

Reisolation of liposomes and $\beta-V L D L$ after coincubation. Unlabeled $\beta$-VLDL was dialyzed against $50 \mathrm{mM}$ sodium phosphate buffer, $\mathrm{pH} 7.4$. Phosphatidylcholine liposomes were prepared by sonication in $50 \mathrm{mM}$ sodium phosphate buffer. Aliquots of dialyzed $\beta$-VLDL, each containing $18 \mathrm{mg}$ protein, were incubated for $2 \mathrm{~h}$ at $37^{\circ} \mathrm{C}$ with either buffer (control) or with $900 \mathrm{mg}$ of liposomal phospholipid in $50 \mathrm{mM}$ phosphate buffer.
Incubated mixtures were then applied to $2.5 \times 30$-cm beds of hydroxyapatite, and unbound material was eluted with $50 \mathrm{mM}$ phosphate buffer. Bound material was then eluted by a linear gradient of phosphate concentrations, from 50 to $650 \mathrm{mM}$, as previously described $(13,31)$.

Fractions eluted from the hydroxyapatite columns were analyzed for their content of phospholipid (24), cholesterol, cholesteryl ester (23), protein (32), and protein species (18). Reisolated vesicles were identified by a high content of phospholipid with little cholesteryl ester (13) and no apoB $(13,31)$. Reisolated $\beta$-VLDL was identified by its high content of cholesteryl ester and apoB.

Competitive binding studies. Human foreskin fibroblasts, frozen in the 6 th-8th passage, were thawed, plated at $10^{5}$ cells per $35 \mathrm{~mm}$ dish, and grown to subconfluency in DMEM/FCS. The cells were then grown to near-confluency in 5\% lipoprotein-deficient FCS, to stimulate the activity of LDL receptors (30). Competitive displacement studies were conducted at $4^{\circ} \mathrm{C}$ between ${ }^{125} \mathrm{I}-\mathrm{LDL}$ and unlabeled particles isolated from incubated mixtures of $\beta$-VLDL with or without liposomes (30).

Statistical analyses. Unless otherwise stated, values for which errors are given are means \pm SEM for three separate determinations $(n=3)$.

\section{Results}

Modification by liposomes of cellular accumulation of cholesterol. J774 cells were preloaded with $\left[{ }^{3} \mathrm{H}\right]$ cholesterol, then incubated for $18 \mathrm{~h}$ in DMEM/fBSA (plasma-free control), or in control medium supplemented with $10 \%$ (vol/vol) hypercholesterolemic rabbit plasma obtained just before or $20 \mathrm{~min}$ after a single intravenous bolus of $300 \mathrm{mg}$ phospholipid/kg body wt (Fig. 1). Incubation with preinfusion, hypercholesterolemic plasma in-

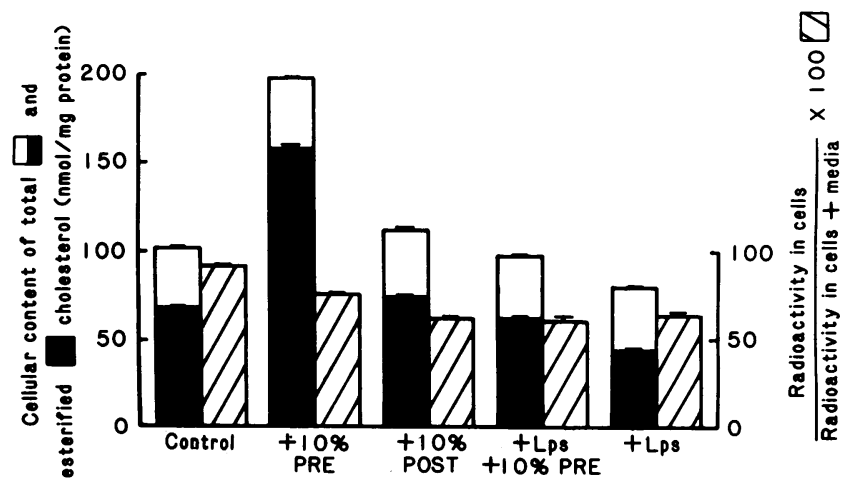

Figure 1. Effect of a phospholipid infusion on the ability of plasma from a hypercholesterolemic rabbit to cause cholesterol loading and cholesterol efflux from J774 macrophages. J774 macrophages were preloaded with cholesterol mass and radioactivity by an 18-h incubation at $37^{\circ} \mathrm{C}$ with $\left[\left(7-{ }^{3} \mathrm{H}\right)\right.$-cholesteryl ester $]-L D L$ in DMEM with $10 \%$ (vol/vol) FCS. Preloaded cells were washed, then incubated for an additional $18 \mathrm{~h}$ in DMEM plus $1.5 \% \mathrm{fBSA}$ (control), or in control medium supplemented with $10 \%$ ( $\mathrm{vol} / \mathrm{vol}$ ) hypercholesterolemic rabbit plasma obtained just before $(+10 \%$ PRE) or $20 \mathrm{~min}$ after $(+10 \%$ POST) a single bolus infusion of $300 \mathrm{mg}$ liposomal phospholipid/kg body weight. Additional wells of preloaded cells were incubated in $10 \%$ preinfusion plasma plus $0.6 \mathrm{mg}$ egg phosphatidylcholine/ml medium (+ Lps + 10\% PRE), or egg phosphatidylcholine without plasma (+ Lps). Plasma cholesterol concentrations were $9.8 \mathrm{mmol} /$ liter before the infusion and $9.5 \mathrm{mmol} / \mathrm{liter}$ at $20 \mathrm{~min}$ after the infusion. Cells and media were separately counted for cholesterol radioactivity following these incubations; the percentage of total radioactivity (i.e., in cells plus media) remaining in the cells was then computed. Displayed are means and standard errors of the means for total cellular cholesterol $(\square)$, cholesteryl ester ( $\square$ ), and retained radioactivity ( $($ ) from a representative experiment. These values were determined from three separate tissue culture wells in each experimental group. Cellular viabilities by trypan blue exclusion were $85-94 \%$. 
creased the cellular contents of total cholesterol and cholesteryl ester to approximately twice the control values (Fig. 1). In contrast, incubation with postinfusion plasma from the same rabbit resulted in essentially no net cellular accumulation of either total cholesterol or cholesteryl ester compared to control (Fig. 1).

Performing this experiment with a range of cholesterol contents in the preloaded, control cells (101.2, 153.4, and 181.3 nmol total cholesterol/mg protein) and a range of cholesterol concentrations in the preinfusion, hypercholesterolemic plasma (7.3, 9.8, and $11.5 \mathrm{mmol} / \mathrm{liter})$ produced the same results: preinfusion plasmas consistently caused large increases in total cellular cholesterol and cholesteryl ester over control, whereas postinfusion plasmas resulted in total cholesterol and cholesteryl ester contents nearly identical to control (not displayed). Thus, although the preinfusion, hypercholesterolemic rabbit plasmas were extremely potent in cholesterol-loading the cells, plasmas obtained from the same rabbits 20 min after a phospholipid infusion were nearly inert.

Despite the large difference in cellular cholesterol content between $\mathrm{J} 774$ cells incubated with pre- and postinfusion hypercholesterolemic plasma, a comparatively small difference was observed in the amount of cholesterol radioactivity retained by these cells (Fig. 1, hatched bars). The cells retained 19\% less total cholesterol radioactivity in postinfusion plasma than in preinfusion plasma, but the total cholesterol mass was $44 \%$ less. Phospholipid-enrichment of hypercholesterolemic plasma in vivo by infusion or in vitro by adding liposomes to preinfusion plasma produced nearly identical effects on cellular cholesterol mass and radioactivity (Fig. 1). Phospholipid liposomes without plasma produced parallel losses of cholesterol mass and radioactivity (Fig.1).

Similar impairment of cholesterol loading was seen with mouse peritoneal macrophages. Mouse peritoneal macrophages were preloaded with $\left[{ }^{3} \mathrm{H}\right]$ cholesterol by incubation with acetylLDL. Preloaded cells were then incubated for $18 \mathrm{~h}$ in DMEM/ fBSA (control) or in control medium supplemented with $\beta$ VLDL alone ( $300 \mu \mathrm{g}$ total cholesterol $/ \mathrm{ml}$ ) or with $\beta$-VLDL and liposomes (1.1 mg sonicated phospholipid/ml). Incubation with $\beta$-VLDL in the absence of liposomes increased cellular total cholesterol content to $134 \% \pm 1.8 \%$ of control, while the cells retained $66.3 \% \pm 0.27 \%$ of their preloaded cholesterol radioactivity. Incubation with $\beta$-VLDL in the presence of liposomes resulted in a cellular cholesterol content of $98 \% \pm 1.2 \%$ of control, and the cells retained $62.3 \% \pm 0.25 \%$ of their preloaded radioactivity. Thus, liposomes abolished the ability of $\beta$-VLDL to cholesterol-load mouse peritoneal macrophages, while having essentially no effect in the presence of $\beta$-VLDL on cellular retention of cholesterol radioactivity.

Modification by liposomes of cellular uptake of $\beta-V L D L$. The contrasting effects on cholesterol mass and retained cholesterol radioactivity in $\mathrm{J} 774$ and mouse peritoneal macrophages strongly suggest that decreased accumulation of cellular cholesterol in the presence of liposomes does not primarily result from enhanced cholesterol efflux, but is rather the result of decreased uptake of $\beta$-VLDL cholesterol from the media. To measure directly the cellular uptake of $\beta$-VLDL from pre- and postinfusion plasma, $\mathrm{J774}$ macrophages were incubated for $5 \mathrm{~h}$ at $37^{\circ} \mathrm{C}$ in DMEM supplemented with ${ }^{125} \mathrm{I}-\beta$-VLDL $(0.4 \mu \mathrm{g}$ protein $/ \mathrm{ml})$ and either $10 \%$ preinfusion hypercholesterolemic rabbit plasma or $10 \%$ plasma obtained from the same rabbit 20 min after a single bolus of $300 \mathrm{mg}$ liposomes $/ \mathrm{kg}$ body weight. Cell-association and degradation of ${ }^{125} \mathrm{I}-\beta$-VLDL in $10 \%$ postinfusion hy- percholesterolemic rabbit plasma were only $13.3 \% \pm 0.2 \%$ and $9.4 \% \pm 0.3 \%$, respectively, of the values in $10 \%$ preinfusion plasma. Similarly, the cell-association of $\left[\left({ }^{3} \mathrm{H}\right)\right.$-cholesteryl ester]$\beta$-VLDL in postinfusion plasma was $26.4 \% \pm 0.5 \%$ of the value in preinfusion plasma. These results document that cellular uptake and degradation of $\beta$-VLDL is markedly reduced in the presence of liposomes.

The reduction in cell-association and degradation of ${ }^{125} \mathrm{I}-\beta$ VLDL also occurred when sonicated phospholipid was added to isolated ${ }^{125} \mathrm{I}-\beta$-VLDL in the absence of plasma. In dose-response experiments, there was a progressive decrease in cellassociation (not displayed) and degradation (Fig. 2) of isolated ${ }^{125} \mathrm{I}-\beta$-VLDL with increasing amounts of liposomal phospholipid. The results were identical for $\mathbf{J} 774$ cells ( filled circles) and mouse peritoneal macrophages (open circles). The maximum effect was reached at a 43:1.0 mass ratio of liposomal phospholipid to $\beta$ VLDL protein, which corresponds to a 2.9:1.0 molar ratio of liposomal phospholipid to $\beta$-VLDL cholesterol.

Mechanism of blocked cellular uptake of $\beta$-VLDL: possible alterations in the cells. To determine the mechanism of phospholipid-induced blockage of $\beta$-VLDL uptake and degradation by model foam cells, we first examined if the effect was the result of alterations in the cells. By trypan blue exclusion, phospholipid liposomes over a wide range of concentrations had no effect on the viability of $\mathbf{J} 774$ cells or mouse peritoneal macrophages (Figs. 1 and 2). In addition, J774 cells shown to be nearly incapable of degrading ${ }^{125} \mathrm{I}-\beta-\mathrm{VLDL}$ in the presence of liposomes were capable of fully normal rates of degradation when the liposomecontaining media were removed and immediately replaced with ${ }^{125} \mathrm{I}-\beta$-VLDL in liposome-free media (Fig. 3). Cell survival and lipoprotein degradation pathways thus had remained normal.

Mechanism of blocked cellular uptake of $\beta-V L D L$ : alterations in the lipoproteins. We next examined if phospholipid-induced blockage of $\beta$-VLDL uptake and degradation was the result of alterations in the lipoproteins in the media. Liposomal phos-

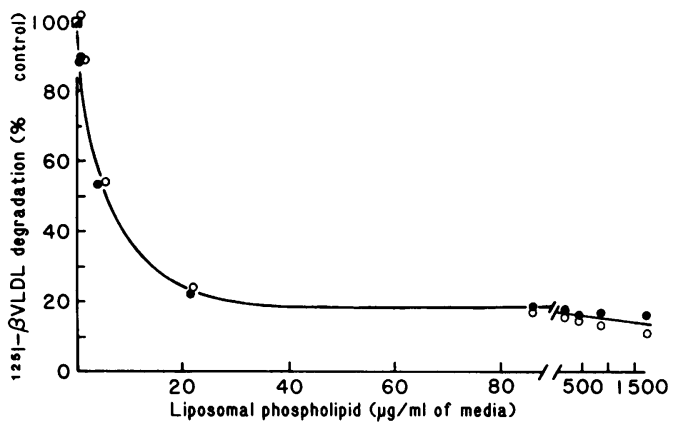

Figure 2. Dose response of added phospholipid on ${ }^{125} \mathrm{I}-\beta$-VLDL degradation by cultured macrophages. J774 cells $(\bullet)$ were incubated for $4 \mathrm{~h}$ and mouse peritoneal macrophages (o) were incubated for $5 \mathrm{~h}$ at $37^{\circ} \mathrm{C}$ in DMEM supplemented with $0.1 \% \mathrm{fBSA}, 0.5 \mu \mathrm{g}{ }^{125} \mathrm{I}-\beta$-VLDL protein $/ \mathrm{ml}$, and the indicated concentrations of sonicated egg phosphatidylcholine. Cell-specific degradation of ${ }^{125} \mathrm{I}-\beta$-VLDL protein was then determined. Degradation of ${ }^{125} \mathrm{I}-\beta$-VLDL in the absence of added phospholipid ( $100 \%$ on the $y$-axis) ( $\square$ ) by $\mathrm{J} 774$ cells was $0.3 \mu \mathrm{g} / \mathrm{mg}$ cellular protein and by mouse peritoneal macrophages was $0.8 \mu \mathrm{g} / \mathrm{mg}$ cellular protein. Displayed are means for values obtained in three separate culture wells in each experimental group. Maximum standard errors of the means were $\pm 3.4 \%$ for $\mathrm{J} 774$ cells and $\pm 2.1 \%$ for mouse peritoneal macrophages. Cell viabilities were $70-90 \%$ for the $\mathrm{J} 774$ cells and $75-80 \%$ for the mouse peritoneal macrophages; viabilities did not vary systematically with the concentration of egg phosphatidylcholine. 


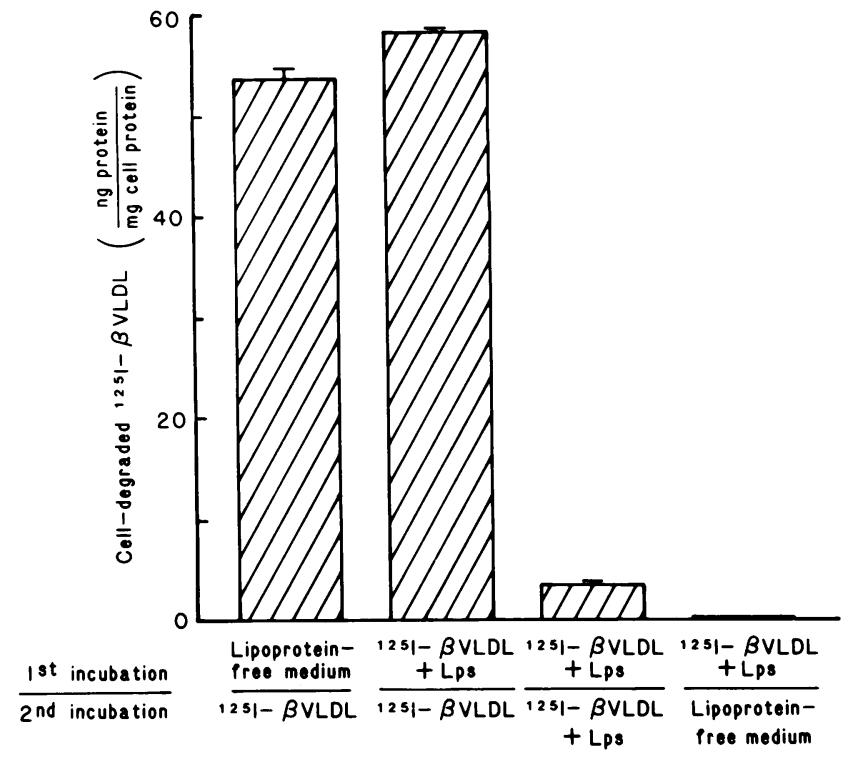

Figure 3. Degradation of ${ }^{125} \mathrm{I}-\beta-\mathrm{VLDL}$ by $\mathrm{J} 774$ cells that had been previously incubated with ${ }^{125} \mathrm{I}-\beta$-VLDL and liposomes. J774 cells were subjected to two sequential $5 \mathrm{~h}$ incubations at $37^{\circ} \mathrm{C}$ in lipoprotein-free media supplemented with $0.4 \mu \mathrm{g}{ }^{125} \mathrm{I}-\beta$-VLDL protein $/ \mathrm{ml}$ and $0.6 \mathrm{mg}$ liposomal (Lps) phospholipid/ml, as indicated. During the first incubation, degradation of ${ }^{125} \mathrm{I}-\beta$-VLDL in the presence of phospholipid liposomes was $3.53 \pm 0.16 \mathrm{ng}$ protein $/ \mathrm{mg}$ cell protein $(n=9)$. Degradation of ${ }^{125} \mathrm{I}-\beta$-VLDL during the second incubation is shown. Displayed are means and standard errors of the means for three separate determinations.

pholipid $(900 \mathrm{mg}$ ) was incubated with isolated $\beta$-VLDL ( $18 \mathrm{mg}$ protein). Vesicular particles were then separated from the $\beta$ VLDL by hydroxyapatite chromatography.

Two populations of vesicular particles were isolated from the hydroxyapatite column, one that eluted in the initial 50$\mathrm{mM}$ phosphate buffer (vesicles I) and one that eluted at the beginning of the phosphate gradient (vesicles II). Reisolated $\beta$ VLDL eluted toward the end of the phosphate gradient. The absence of $\beta$-VLDL in vesicles I and II was verified by the lack of apoB, as determined by dodecyl sulfate-polyacrylamide gel electrophoresis (Fig. 4), and the low contents of cholesteryl ester ( $\leq 0.6 \mathrm{mass} \%$ in these preparations). Both vesicles I and II acquired unesterified cholesterol from $\beta$-VLDL. In addition, both preparations acquired protein from $\beta$-VLDL, although the mass ratio of protein to phospholipid in vesicles II was approximately six times the ratio in vesicles $I$. Because the predominant protein in both preparations was apoE (Fig. 4), the higher mass ratio of protein to phospholipid in vesicles II indicates a higher apoE content.

In competitive displacement studies, vesicles I and II showed potent receptor binding, whereas protein-free phospholipid liposomes had little effect (Fig. $5 \mathrm{~A}$ ). Of the two preparations of reisolated vesicles, vesicles II showed greater receptor affinity (Fig. $5 \mathrm{~A}$ ), consistent with its greater apoE content.

Compared to $\beta$-VLDL that had been incubated without liposomes then subjected to hydroxyapatite chromatography (control $\beta$-VLDL), the $\beta$-VLDL reisolated after incubation with liposomes ( $\beta$-VLDL-PPL) became phospholipid enriched, while losing about half its unesterified cholesterol and a quarter of its protein. The reisolated $\beta$-VLDL-PPL still contained apoE detectable by polyacrylamide gel electrophoresis; however, $50 \%$

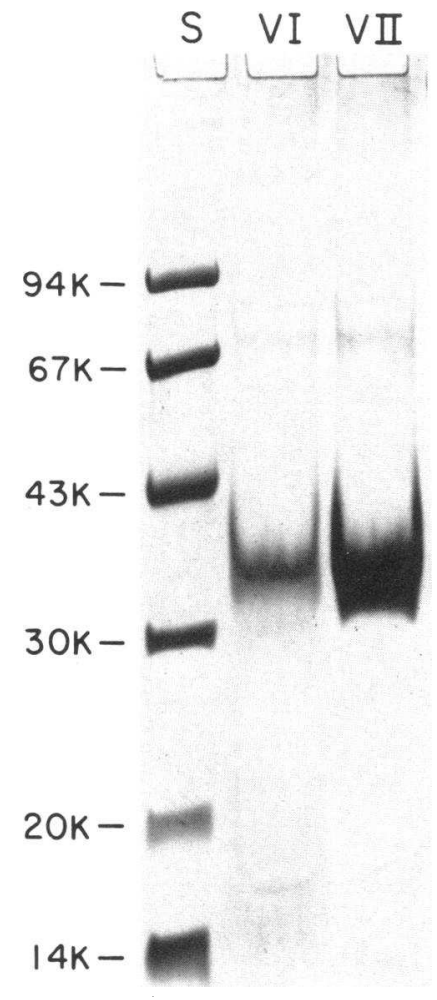

Figure 4. Protein species acquired by phospholipid vesicles during incubation with $\beta$ VLDL. Phospholipid vesicles were incubated with $\beta$-VLDL, then reisolated by hydroxyapatite chromatography, as described in the text. Reduced, delipidated samples were subjected to protein electrophoresis on a dodecyl sulfate-polyacrylamide gradient $(6-16 \%)$ gel. Lane $S$, molecular weight standards. Lane $V I$, vesicles I. Lane $V I I$, vesicles II. The heavily stained bands in lanes $V I$ and $V I I$ comigrated with the apoE band of rabbit $\beta$-VLDL.

inhibition of ${ }^{125} \mathrm{I}-\mathrm{LDL}$ receptor binding required approximately three times as much $\beta$-VLDL-PPL as control $\beta$-VLDL (Fig. 5 $B$ ). Thus, during coincubation, liposomes acquired apoE and receptor reactivity, while $\beta$-VLDL lost apoE and receptor reactivity.

Time course of the cholesterol-loading ability of hypercholesteremic rabbit plasma following an infusion of liposomes. For these observations to have relevance to atherosclerosis, infused liposomes must produce sustained alterations in the cholesterolloading ability of hypercholesterolemic rabbit plasma. We therefore examined the cholesterol-loading abilities of plasma samples obtained before and up to $24 \mathrm{~h}$ after a single infusion of phospholipid liposomes. After the infusion, plasma phospholipid concentration rose, declined rapidly in the first hour, then declined more gradually from 1 to $24 \mathrm{~h}$ (Fig. $6 \mathrm{~A}$ ). The gradual disappearance of excess phospholipid from the circulation is consistent with prior reports of prolonged half-lives for cholesterol-free liposomes infused in large doses $(>25-100 \mathrm{mg} / \mathrm{kg}$ body weight) $(11,12,33,34)$.

Following the infusion, the plasma concentration of unesterified cholesterol initially fell. This fall was seen in all phospholipid-infused, hypercholesterolemic rabbits, and coincided with the initial, rapid clearance of phospholipid. From $20 \mathrm{~min}$ to $24 \mathrm{~h}$ after the phospholipid infusion, the plasma concentration of unesterified cholesterol steadily rose (Fig. $6 \mathrm{~A}$ ), consistent with the findings of previous studies $(3,5,11,12,35-38)$. Plasma cholesteryl ester concentration rose slightly following the infusion and returned to the preinfusion value by $24 \mathrm{~h}$ (Fig. $6 \mathrm{~A}$ ).

Impairment of the ability of hypercholesterolemic plasma to cause cholesterol accumulation in cultured macrophages lasted for hours following a phospholipid infusion (Fig. $6 \mathrm{~B}$ ). Plasma obtained $4 \mathrm{~h}$ after a phospholipid bolus behaved identically to plasma obtained $20 \mathrm{~min}$ after the bolus. By 8-24 h, some of the original loading ability had returned, but cellular accumulation 


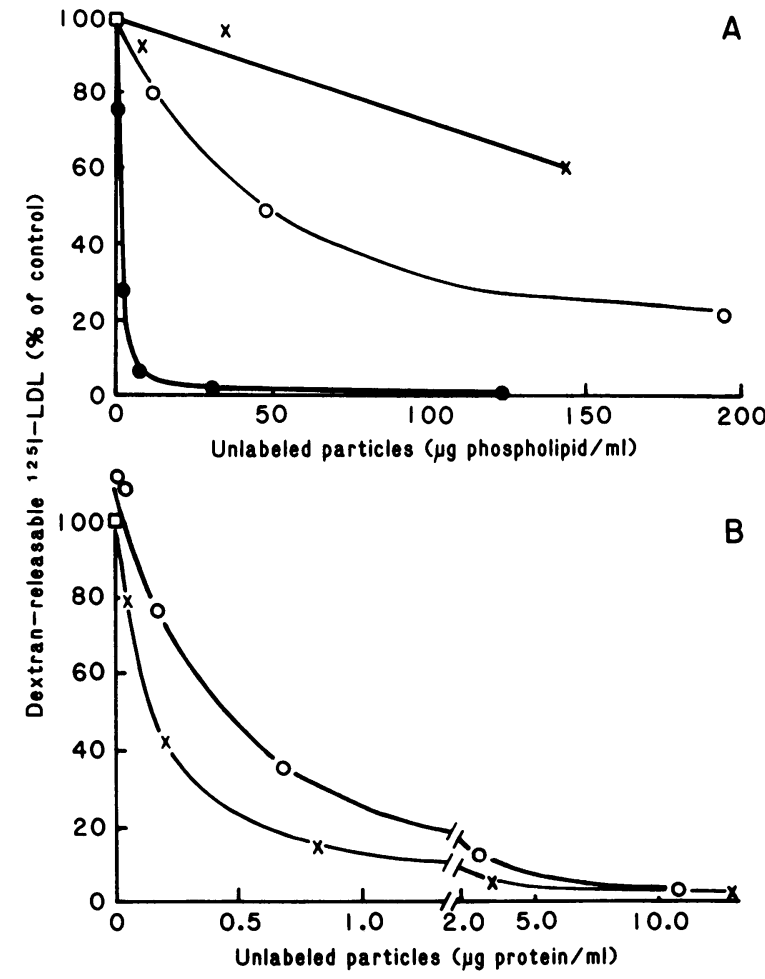

Figure 5. Competitive displacement of ${ }^{125}$ I-LDL by sonicated phospholipid and by particles reisolated from incubated mixtures of $\beta$ VLDL with buffer or with sonicated phospholipid. Incubations and reisolations are described in the text. Human neonatal foreskin fibroblasts grown to near confluency in DMEM with lipoprotein-deficient serum were incubated for $2 \mathrm{~h}$ at $4^{\circ} \mathrm{C}$ with media containing $1.0 \mu \mathrm{g}$ ${ }^{125} \mathrm{I}-\mathrm{LDL}$ protein $/ \mathrm{ml}$ and the indicated concentrations of competing particles. The cells were then washed, and dextran-releasable radioactivity was measured, from which the mass of dextran-releasable ${ }^{125} \mathrm{I}$ LDL protein was calculated. Binding of ${ }^{125} \mathrm{I}-\mathrm{LDL}$ in the absence of competing articles (100\% on the $y$-axes) ( $\square$ ) was $89.8 \mathrm{ng}{ }^{125} \mathrm{I}-\mathrm{LDL}$ protein/mg cellular protein. $(A) \times$, sonicated phospholipid; $\bigcirc$, reisolated vesicles I; $\bullet$, reisolated vesicles II. (B) $\times$, control $\beta$-VLDL; $\propto, \beta$-VLDLPPL. Each point represents the mean of two determinations.

of cholesterol was still far less than in preinfusion plasma (Fig. $6 \mathrm{~B})$. Efflux of $\left[{ }^{3} \mathrm{H}\right]$ cholesterol from the cells was essentially identical in all plasma samples from preinfusion to $24 \mathrm{~h}$ postinfusion, despite considerable variation in the cholesterol/phospholipid molar ratio in these plasmas (Fig. $6 \mathrm{~B}$ ).

\section{Discussion}

We conclude that a single intravenous bolus of phospholipid promptly abolishes the ability of plasma from cholesterol-fed rabbits to cause cholesterol accumulation in model foam cells. The effect persists for at least $24 \mathrm{~h}$ after the infusion, and primarily results from blockage of cellular uptake of $\beta$-VLDL.

Blockage of $\beta$-VLDL uptake is the result of two modifications of the plasma lipoproteins. First, a vesicular lipoprotein is formed $(11,12)$ that contains apoE but has no cholesteryl ester core. Vesicular lipoproteins are internalized and degraded by cultured cells (13), but they have a far lower ratio of total cholesterol to apoE than is found in $\beta$-VLDL. Thus, these particles competitively block receptor-mediated uptake of cholesteryl ester-rich
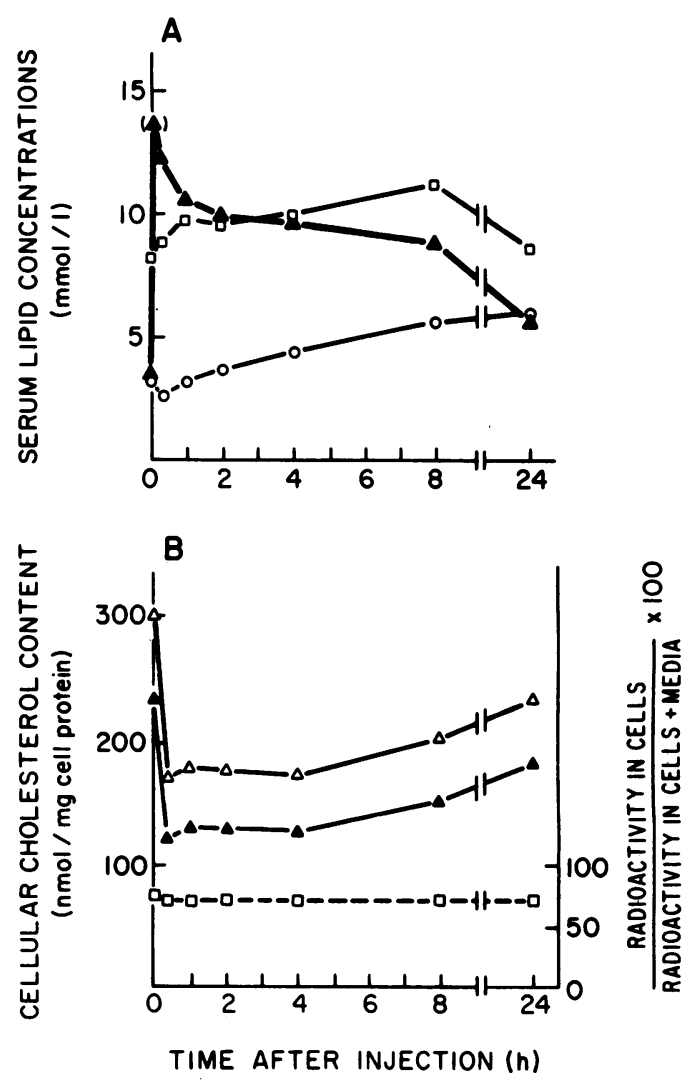

Figure 6. Time course of the cholesterol-loading ability of hypercholesterolemic rabbit plasma after an infusion of liposomes. $\mathbf{J 7 7 4}$ macrophages were preloaded with cholesterol mass and radioactivity by a 2 $h$ incubation at $37^{\circ} \mathrm{C}$ with $\left[\left({ }^{3} \mathrm{H}\right)\right.$-cholesteryl ester $]$-acetyl-LDL in DMEM with $10 \%$ FCS. Cells were washed, then incubated for an additional $18 \mathrm{~h}$ in DMEM, 0.1\% fBSA, and 10\% hypercholesterolemic rabbit plasma obtained just before $(t=0 \mathrm{~h})$ or at the indicated times after a bolus infusion of $\mathbf{4 0 0} \mathrm{mg}$ liposomal phospholipid/kg body weight. $(A)$ Concentrations of phospholipid ( $\triangle)$, cholesteryl ester ( $\square$ ), and unesterified cholesterol ( $(0)$ in the plasma samples. The maximum phospholipid concentration (shown in parentheses) was calculated based on the measured dose of phospholipid, a preinfusion phospholipid concentration of $3.36 \mathrm{mmol} / \mathrm{liter}$, and an estimated $50 \mathrm{ml}$ plasma/kg body weight. $(B)$ Mean cellular contents of total cholesterol $(\Delta)$, cholesteryl ester $(\Delta)$, and retained radioactivity $(\square)$ following the 18-h incubation with plasma obtained at the indicated times. Three separate culture wells were used in each experimental group. Maximum standard errors of the mean were $\pm 8.0 \mathrm{nmol} / \mathrm{mg}$ for total cellular cholesterol, $\pm 7.7 \mathrm{nmol} / \mathrm{mg}$ for cellular cholesteryl ester, and $\pm 0.6 \%$ for retained radioactivity.

$\beta$-VLDL, without causing significant cellular accumulation of cholesterol. Second, $\beta$-VLDL loses apoE to this vesicular particle, and thereby directly loses receptor affinity. Further loss of receptor affinity might occur through the compositional changes in $\beta$-VLDL surface lipids (cf. 39). As an additional effect on cellular cholesterol balance, liposomes introduced into hypercholesterolemic rabbit plasma produced a variable and small enhancement of cholesterol efflux from cultured macrophages. Liposomes in vivo produce a more consistent enhancement of cellular cholesterol efflux (ref. 12; see also Fig. $6 \mathrm{~A}$ ).

Our finding of blocked $\beta$-VLDL uptake by cultured macrophages may be relevant to cholesterol metabolism in arterial wall macrophages. The arterial wall of cholesterol-fed rabbits expresses large numbers of receptors for $\beta$-VLDL (1). Receptor- 
mediated uptake of $\beta$-VLDL by the arterial wall in vivo may be susceptible to blockage by infused liposomes by the mechanisms we demonstrated in vitro. In contrast, the liver of cholesterolfed rabbits contains few lipoprotein receptors, and these are saturated (40). Despite impaired hepatic receptors (40), substantial hepatic uptake of $\beta$-VLDL has been demonstrated in cholesterolfed rabbits (41), and the total catabolic rate of $\beta$-VLDL in cholesterol-fed rabbits is at least ten times greater than in normal rabbits (42). These observations suggest that a significant portion of hepatic uptake of $\beta$-VLDL in cholesterol-fed rabbits is receptor independent, and would not be susceptible to blockage by apoEcontaining liposomes. Thus, in the cholesterol-fed animal, infused liposomes might direct $\beta$-VLDL away from arterial wall macrophages and toward the liver.

Atherogenic $\beta$-VLDL appears in the plasma of cholesterolfed animals during the period of cholesterol feeding and can persist for months following restoration to a normal diet $(4,42)$. During the persistent hypercholesterolemia that follows cessation of cholesterol-rich diets, there is continued synthesis of $\beta$-VLDL and continued arterial wall uptake of $\beta$-VLDL (42). Regression and prevention of experimental atherosclerosis by phospholipid infusions have been documented during continued cholesterol feeding (7-10) and during this phase of persistent hypercholesterolemia (4). Our demonstration in vitro that liposomes block uptake of $\beta$-VLDL by macrophages suggests that the antiatherogenic effects of phospholipid infusions during atherogenic hyperlipidemia may result in part from blockage of $\beta$-VLDL uptake by arterial wall foam cells, while hepatic clearance is preserved.

Phospholipid liposomes also inhibit cholesterol-loading of cultured macrophages by plasma rich in LDL, the major atherogenic lipoprotein in many types of human plasma. Incubation of J774 macrophages with LDL-rich plasma from a Watanabe Heritable Hyperlipidemic rabbit (26) increased cellular total and esterified cholesterol contents to $346 \%$ and $718 \%$ of control, respectively. Incubation with plasma plus $1.2 \mathrm{mg}$ sonicated egg phosphatidylcholine/ml medium resulted in total and esterified cholesterol contents that were only 131 and $154 \%$ of control (Williams, K. J., T. Donnelly, T. Parker, and A. R. Tall, unpublished data). As a general concept, phospholipid-rich, cholesterol-poor particles, such as vesicular lipoproteins or phospholipid-enriched HDL, may acquire apoE in atherogenic plasma, then compete with atherogenic particles for receptormediated uptake by foam cells.

\section{Acknowledgments}

This work was supported by National Institutes of Health grant HL22682 and by a Clinician-Scientist Award to K. J. Williams from the American Heart Association and E. R. Squibb \& Sons Company, with funds contributed in part by the AHA-New York City Affiliate.

\section{References}

1. Pitas, R. E., T. L. Innerarity, and R. W. Mahley, 1983. Foam cells in explants of atherosclerotic rabbit aortas have receptors for $\beta$-very low density lipoproteins and modified low density lipoproteins. Arteriosclerosis. 3:2-12.

2. Koo, C., M. E. Wernette-Hammond, and T. L. Innerarity. 1986. Uptake of canine $\beta$-very low density lipoproteins by mouse peritoneal macrophages is mediated by a low density lipoprotein receptor. J. Biol. Chem. 261:11194-11201.
3. Friedman, M., S. O. Byers, and R. H. Rosenman. 1957. Resolution of aortic atherosclerotic infiltration in the rabbit by phosphatide infusion. Proc. Soc. Exp. Biol. Med. 95:586-588.

4. Byers, S. O., and M. Friedman. 1960. Effect of infusions of phosphatides upon the atherosclerotic aorta in situ and as an ocular aortic implant. J. Lipid Res. 1:343-348.

5. Maurukas, J., and R. G. Thomas. 1960. Treatment of experimental atherosclerosis in the rabbit with L,D. alpha (dimyristoyl) lecithin. $J$. Lab. Clin. Med. 56:30-37.

6. Adams, C. W. M., Y. H. Abdulla, O. B. Bayliss, and R. S. Morgan. 1967. Modification of aortic atheroma and fatty liver in cholesterol-fed rabbits by intravenous injection of saturated and polyunsaturated lecithins. J. Pathol. Bacteriol. 94:77-87.

7. Patelski, J., D. E. Bowyer, A. N. Howard, I. W. Jennings, C. J. R. Thorne, and G. A. Gresham. 1970. Modification of enzyme activities in experimental atherosclerosis in the rabbit. Atherosclerosis. 12:41-53.

8. Howard, A. N., J. Patelski, D. E. Bowyer, and G. A. Gresham. 1971. Atherosclerosis induced in hypercholesterolaemic baboons by immunological injury; and the effects of intravenous polyunsaturated phosphatidyl choline. Atherosclerosis. 14:17-29.

9. Altman, R. F. A., J. M. de Mendonça, G. M. V. Schaeffer, J. Ramos de Souza, J. G. Bandoli, D. J. da Silva, and C. R. N. Lopes. 1974. Phospholipids in experimental atherosclerosis. Arzneim. Forsch. 24:11-16.

10. Stafford, W. W., and C. E. Day. 1975. Regression of atherosclerosis effected by intravenous phospholipid. Artery. 1:106-114.

11. Williams, K. J., V. P. Werth, and J. A. Wolff. 1984. Intravenously administered lecithin liposomes: a synthetic antiatherogenic lipid particle. Perspect. Biol. Med. 27:417-431.

12. Williams, K. J., and A. M. Scanu. 1986. Uptake of endogenous cholesterol by a synthetic lipoprotein. Biochim. Biophys. Acta. 875:183194.

13. Williams, K. J., A. R. Tall, I. Tabas, and C. Blum. 1986. Recognition of vesicular lipoproteins by the apolipoprotein B,E receptor of cultured fibroblasts. J. Lipid Res. 27:892-900.

14. Williams, K. J., A. Tall, and C. Bisgaier. 1986. Phospholipid liposomes acquire apo-E in atherogenic plasma and inhibit cholesterol loading of macrophages. Circulation. 74(Suppl. II):197. (Abstr.)

15. Havel, R. J., H. A. Eder, and J. H. Bragdon. 1955. The distribution and chemical composition of ultracentrifugally separated lipoproteins in human serum. J. Clin. Invest. 34:1345-1353.

16. Fraenkel-Conrat, H. 1957. Methods for investigating the essential groups for enzyme activity. Methods Enzymol. 4:247-269.

17. Bilheimer, D. W., S. Eisenberg, and R. I. Levy. 1972. The metabolism of very low density lipoprotein proteins. I. Preliminary in vitro and in vivo observations. Biochim. Biophys. Acta. 260:212-221.

18. Weber, K., and M. Osborn. 1969. The reliability of molecular weight determinations by dodecyl sulfate-polyacrylamide gel electrophoresis. J. Biol. Chem. 244:4406-4412.

19. Ihm, J., J. A. K. Harmony, J. Ellsworth, and R. L. Jackson. 1980. Simultaneous transfer of cholesteryl ester and phospholipid by protein(s) isolated from human lipoprotein-free plasma. Biochem. Biophys. Res. Commun. 93:1114-1120.

20. Mangold, H. K. 1969. Aliphatic lipids. In Thin-layer Chromatography. A Laboratory Handbook. E. Stahl, editor. Springer-Verlag, New York. 363-421.

21. Huang, C., and T. E. Thompson. 1974. Preparation of homogeneous, single-walled phosphatidylcholine vesicles. Methods Enzymol. 32:485-489.

22. Allain, C. C., L. S. Poon, C. S. G. Chan, W. Richmond, and P. C. Fu. 1974. Enzymatic determination of total serum cholesterol. Clin. Chem. 20:470-475.

23. Ishikawa, T. T., J. MacGee, J. A. Morrison, and C. J. Glueck. 1974. Quantitative analysis of cholesterol in 5 to $20 \mu$ l of plasma. $J$. Lipid Res. 15:286-291.

24. Bartlett, G. R. 1959. Phosphorus assay in column chromatography. J. Biol. Chem. 234:466-468. 
25. Tabas, I., D. A. Weiland, and A. R. Tall. 1985. Unmodified low density lipoprotein causes cholesteryl ester accumulation in J774 macrophages. Proc. Natl. Acad. Sci. USA. 82:416-420.

26. Brown, M. S., and J. L. Goldstein. 1983. Lipoprotein metabolism in the macrophage: implications for cholesterol deposition in atherosclerosis. Annu. Rev. Biochem. 52:223-261.

27. Edelson, P. J., and Z. A. Cohn. 1976. Purification and cultivation of monocytes and macrophages. In In Vitro Methods in Cell-mediated and Tumor Immunity. B. R. Bloom and J. R. David, editors. Academic Press, New York. 333-340.

28. Lowry, O. H., N. J. Rosebrough, A. L. Farr, and R. J. Randall. 1951. Protein measurement with the Folin phenol reagent. J. Biol. Chem. 193:265-275.

29. Phillips, H. J. 1973. Dye exclusion tests for cell viability. In Tissue Culture Methods and Applications. P. F. Kruse and M. K. Patterson, editors. Academic Press, New York. 406-408.

30. Goldstein, J. L., S. K. Basu, and M. S. Brown. 1983. Receptormediated endocytosis of low-density lipoprotein in cultured cells. Methods Enzymol. 98:241-260.

31. Danielsson, B., B. G. Johansson, and B. G. Petersson. 1973. Separation of lipoprotein $\mathrm{X}$ and $\beta$-lipoprotein by zonal centrifugation or hydroxyapatite chromatography. Clin. Chim. Acta. 47:365-369.

32. Markwell, M. A. K., S. M. Haas, L. L. Bieber, and N. E. Tolbert. 1978. A modification of Lowry procedure to simplify protein determination in membrane and lipoprotein samples. Anal. Biochem. 87:206210.

33. Hwang, K. J., K-F. S. Luk, and P. L. Beaumier. 1980. Hepatic uptake and degradation of unilamellar sphingomyelin/cholesterol liposomes: a kinetic study. Proc. Natl. Acad. Sci. USA. 77:4030-4034.

34. Untracht, S. H. 1982. Intravascular metabolism of an artificial transporter of triacylglycerols. Alterations of serum lipoproteins resulting from total parenteral nutrition with Intralipid. Biochim. Biophys. Acta 711:176-192.

35. Friedman, M., and S. O. Byers. 1956. Role of hyperphospholipidemia and neutral fat increase in plasma in the pathogenesis of hypercholesteremia. Am. J. Physiol. 186:13-18.

36. Byers, S. O., and M. Friedman. 1956. Independence of phosphatide induced hypercholesteremia and hepatic function. Proc. Soc. Exp. Biol. Med. 92:459-462.

37. Friedman, M., and S. O. Byers. 1958. Enhancement of phosphatide-induced hypercholesteremia by prior ingestion of cholesterol and triglyceride. Am. J. Physiol. 192:546-548.

38. Di Luzio, N. R., and D. B. Zilversmit. 1960. Effect of intravenous phospholipid and Triton on lipids of normal and ethanol-treated rats. Am. J. Physiol. 199:991-994.

39. Zechner, R., H. Dieplinger, A. Roscher, and G. M. Kostner. 1984. The low-density-lipoprotein pathway of native and chemically modified low-density lipoproteins isolated from plasma incubated in vitro. Biochem. J. 224:569-576.

40. Kovanen, P. T., M. S. Brown, S. K. Basu, D. W. Bilheimer, and J. L. Goldstein. 1981. Saturation and suppression of hepatic lipoprotein receptors: a mechanism for the hypercholesterolemia of cholesterol-fed rabbits. Proc. Natl. Acad. Sci. USA. 78:1396-1400.

41. Vallabhajosula, S., M. Paidi, J. J. Badimon, S. J. Goldsmith, and H. N. Ginsberg. 1986. In vivo imaging of ${ }^{99 \mathrm{~m}}$ technetium labeled lipoprotein distribution in normal and hypercholesterolemic rabbits. Arteriosclerosis. 6:560a. (Abstr.)

42. Daugherty, A., G. Schonfeld, B. E. Sobel, and L. G. Lange. 1986. Metabolism of very low density lipoproteins after cessation of cholesterol feeding in rabbits. A factor potentially contributing to the slow regression of atheromatous plaques. J. Clin. Invest. 77:1108-1115. 